\title{
REVIEW
}

\section{EZH2, an epigenetic driver of prostate cancer}

\author{
Yeqing Angela Yang ${ }^{1}$, Jindan $\mathrm{Yu}^{1,2 \bowtie}$ \\ ${ }^{1}$ Division of Hematology/Oncology, Department of Medicine, Northwestern University Feinberg School of Medicine, Chicago, \\ IL 60611, USA \\ ${ }^{2}$ Robert H. Lurie Comprehensive Cancer Center, Northwestern University Feinberg School of Medicine, Chicago, IL 60611, USA \\ $\triangle$ Correspondence: jindan-yu@northwestern.edu
}

Received August 30, 2012 Accepted December 2, 2012

\begin{abstract}
The histone methyltransferase EZH2 has been in the limelight of the field of cancer epigenetics for a decade now since it was first discovered to exhibit an elevated expression in metastatic prostate cancer. It persists to attract much scientific attention due to its important role in the process of cancer development and its potential of being an effective therapeutic target. Thus here we review the dysregulation of EZH2 in prostate cancer, its function, upstream regulators, downstream effectors, and current status of EZH2-targeting approaches. This review therefore provides a comprehensive overview of $\mathrm{EZH} 2$ in the context of prostate cancer.
\end{abstract}

KEYWORDS EZH2, histone methyltransferase, prostate cancer, epigenetics

\section{INTRODUCTION}

Prostate cancer is a major health concern in the older male population worldwide. In 2008, approximately 900,000 men were diagnosed with prostate cancer globally (Center, 2011), and it is currently the sixth most common cause of cancerrelated deaths in the world (Ferlay et al., 2010). In North America, prostate cancer is the most commonly diagnosed non-skin cancer and the second leading cause of cancer mortalities in men. It was estimated that 1 in 6 men will be diagnosed with prostate cancer in their lifetime (Howlader, 2011). Historically, localized prostate cancer has been successfully treated by radical prostatectomy and radiation therapy (Denmeade and Isaacs, 2002), while more advanced cases of prostate cancer are subjected to hormone deprivation therapy (HDT) through surgical (orchiectomy) or chemical castration (LHRH agonists, anti-androgens) (Pienta and Bradley, 2006). Nevertheless, a majority of the tumors can evolve from a hormone-sensitive to a hormone-refractory state, termed castration-resistant prostate cancer (CRPC), which often results in lethality in 1-2 years (Berry et al., 2002; Higano et al., 2009; Lassi and Dawson, 2009; Kantoff et al., 2010a, 2010b). Even with current therapeutic options that are available, such as docetaxel plus prednisone, cabazitaxel, abiraterone acetate, sipuleucel-T as well as the most recently FDA-approved enzalutamide (formerly known as MDV3100) (Shapiro and Tareen, 2012), CRPC still presents a great clinical challenge.

Aided by rapid technological advancements, researchers are now able to better understand the underlying mechanisms of CRPC pathogenesis and exploit innovative strategies for disease treatment. In the past decade, the discovery of EZH2 (enhancer of zeste homolog 2) being a robust biomarker for metastatic prostate cancer sheds new light on developing potential therapeutic approaches. Originally purified and characterized in HeLa cells (Cao et al., 2002) and Drosophila embryos (Czermin et al., 2002; Muller et al., 2002), EZH2 (or E(Z) in flies) has been found to be the catalytic subunit of the Polycomb Repressive Complex (PRC2) responsible for conducting histone methylation. Therefore, with the knowledge that EZH2 is tightly linked to aggressive prostate cancer, understanding how EZH2 contributes to disease progression has gradually made possible the development of epigenetic drugs that directly or indirectly target $\mathrm{EZH} 2$. Hence, this review aims to provide a comprehensive overview of EZH2's molecular involvement in prostate cancer pathogenesis and progression, with particular emphasis on the regulatory network and downstream targets of the histone methyltransferase.

\section{GENETIC AND EPIGENETIC ABERRATIONS IN PROSTATE CANCER ARE OFTEN ASSOCIATED WITH EZH2 STATUS}

Aging and environment have always been considered significant risk factors for prostate cancer. Compelling epidemiological studies demonstrate that dietary habits and stress levels are strongly associated with prostate cancer development. 
While the molecular basis of this link is elicited through the bidirectional interaction between oxidative stress dictated by one's diet and stress level and androgen signaling (Knudsen and Vasioukhin, 2010), the more practical risk factor to be concerned with is in fact the genetic and epigenetic predisposition. Over the past two decades it has been discovered that a wide spectrum of genetic as well as epigenetic aberrations are associated with different stages of prostate cancer development, many of which are connected to EZH2 dysregulation. One of the most prevalent genetic modifications observed to date in prostate cancer is the fusion between the TMPRESS2 and ERG genes, resulted from an abnormal translocation on chromosome 21 (Schulz and Hoffmann, 2009). Detected in more than half of all prostate tumors, this fusion gene consisting of the androgen-responsive TMPRESS2 promoter and the ERG coding region is able to substantially upregulate ERG expression, which has been proven to induce cell proliferation and invasion (Kumar-Sinha et al., 2008). Notably, it has been demonstrated that ERG can directly activate $E Z H 2$, which synergistically result in cancer progression through histone methylationlinked de-differentiation (Yu et al., 2010b).

It is believed that epigenetic changes in prostate cancer appear to be manifested earlier than genetic changes, thus are likely to be more closely related to disease etiology (Nelson et al., 2009). Studies have shown that abnormalities in epigenetic phenomena in prostate cancer, the most remarkable being DNA methylation, can be detected at the earliest stages of transformation (Yegnasubramanian et al., 2004). DNA methylation is another event with close links to $\mathrm{EZH} 2$ activities, since EZH2 can directly interact with several DNA methyltransferases (DNMT1, DNMT3A, DNMT3B) (Sauvageau and Sauvageau, 2010). An extensive list of genes has been reported to exhibit hypermethylation specifically in prostatic tumor cells (Li et al., 2004). Overall a combination of several of them, e.g. GSTP1 and APC, can be subjected to hypermethylation assays to allow a clear and robust discrimination between benign and cancerous prostate cells (Enokida et al., 2005). Moreover, post-translational histone modifications, including $\mathrm{EZH} 2$-induced histone methylation, are another category of epigenetic events playing a crucial role in prostate cancer pathogenesis. Perturbations in histone modifications can heavily impact chromatin structure and genome stability, resulting in inappropriate gene expression or silencing which can lead to cellular transformation (Sparmann and van Lohuizen, 2006). In 2002, through microarray profiling EZH2 was found among the top upregulated genes in aggressive prostate cancer. Studies since then have elaborated in much more details the disease relevance, molecular mechanisms, and therapeutic targeting of $\mathrm{EZH} 2$ in prostate cancer.

\section{EZH2 AS AN EPIGENETIC SILENCER}

DNA in eukaryotes is packaged into repeating units of nucleosomes by winding itself around histone complexes, in a manner comparable to thread wrapping around a spool. The nucleosomes in turn are packed into higher-order structures to allow chromatin compaction, which provides an essential mechanism adopted by mammalian cells to control gene expression (Strahl and Allis, 2000). The local structure of chromatin can heavily influence the degree to which a gene can be transcribed, since it determines how accessible the gene is to the transcriptional machinery, which could be bulky in size and requires opened chromatin so that it can efficiently identify and bind to its recognition sequences. Moreover, specific cofactors and enhancers can form direct interactions with the histone components of a nucleosome, thus providing another level of transcriptional regulation. Over the years through genetic and biochemical studies it has become apparent that histones are undeniably one of the key determinants of local chromatin structure, which is not only affected by histone usage, but also more importantly by covalent post-translational modifications to histone tails.

Polycomb group (PcG) proteins as well as trithorax group ( $T r x G)$ proteins have been discovered to cooperatively maintain the desirable histone patterns by methylating the histone tails for precise gene expression in various cellular processes (Simon and Tamkun, 2002). Playing opposing roles in spite of the fact that both act to modify lysine residues within histone tails, activities of the PcG proteins are associated with repression of transcription while those of Trx proteins are associated with enhancement (Gibbons, 2005).

Assembled into two distinct multiprotein complexes, Polycomb Repressive Complexes (PRC1 and PRC2), the PcG proteins including $\mathrm{EZH} 2$ act in a coordinated manner so that the histones will acquire specific "marks" to allow silencing of tumor suppressor genes (Nelson et al., 2009). Enhancer of zeste homolog 2 (EZH2) is the catalytic member of the PRC2 complex (Fig. 1). EZH2 comprises a SET domain which is recognized as the signature of methyltransferases as it provides the active site for the covalent methylation reaction, resulting in trimethylation (me3) of histone $3(\mathrm{H} 3)$ at lysine $27(\mathrm{~K} 27)$, as well as at lysine 9 (K9) albeit to a much lesser extent (Rea et al., 2000). $\mathrm{EZH} 2$ alone exhibits no intrinsic enzymatic function, in order to be catalytically active it must interact with at least two proteins, embryonic ectoderm development (EED) and suppressor of zeste 12 (SUZ12). As depicted in Fig. 1, these three proteins, with the addition of the histone binding proteins retinoblastoma binding protein 4 (RBBP4) and RBBP7, form the core components of PRC2 (Chase and Cross, 2011). In the mean time, it is known that PRC1 is a key collaborator with PRC2 during epigenetic silencing by ubiquinating histone $\mathrm{H} 2 \mathrm{~A}$ at lysine 119 , and it is composed of B lymphoma Mo-MLV insertion region 1 (BMI1), as well as ring finger proteins RING1 and RING2 (Wang et al., 2004). The trimethylation of H3K27 mediated by PRC2 is believed to recruit $\mathrm{PRC} 1$ to target gene loci to consolidate the condensed chromatin configuration. Furthermore, in support of this coordinated recruitment and function, the expression of PRC1 and PRC2 proteins is orchestrated through a network of regulatory microRNAs (miRNAs) (Cao et al., 2011). It is proposed that several miRNAs, including miR-181a, miR-181b, 


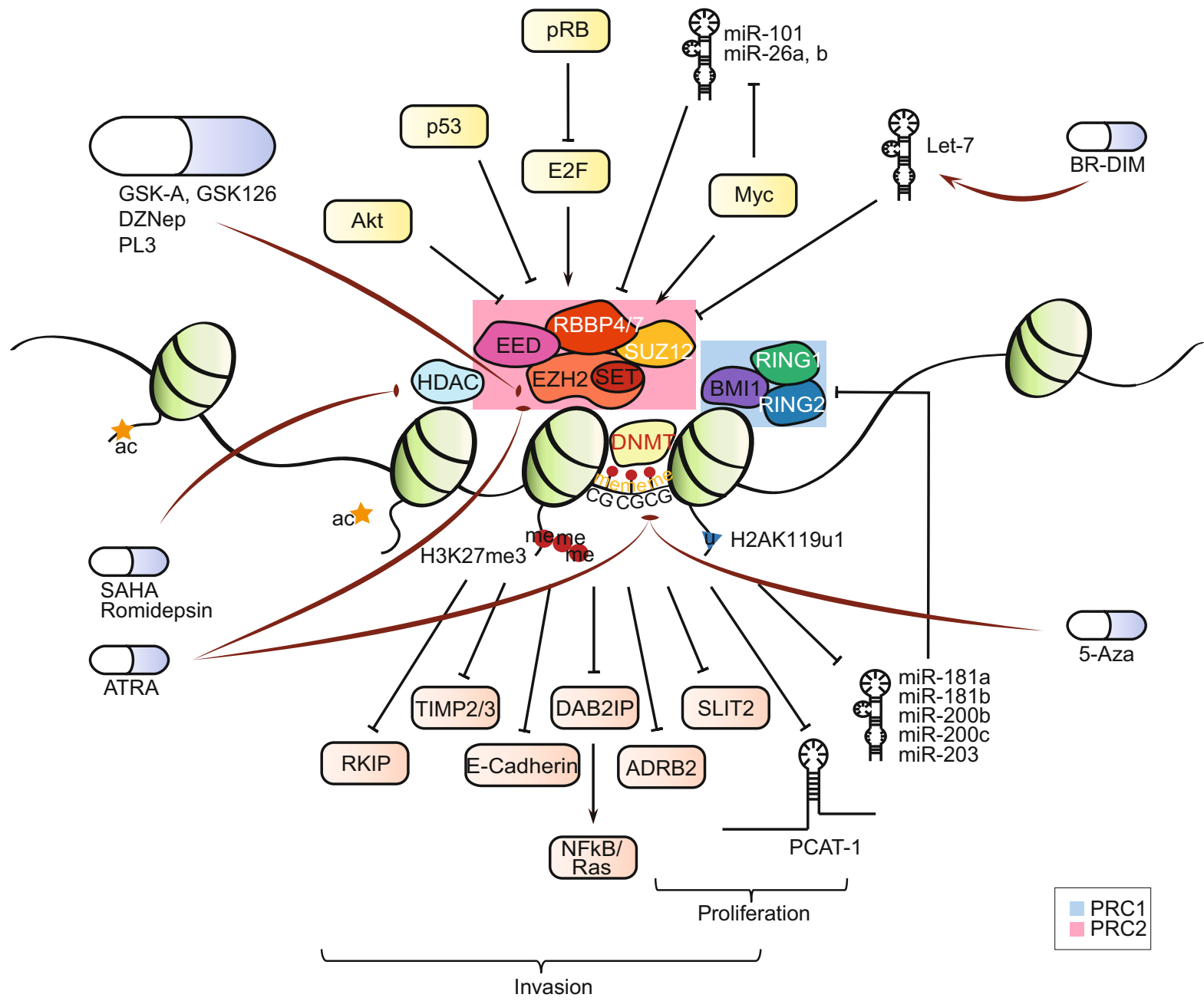

Figure 1. EZH2 regulation and function in prostate cancer. $\mathrm{EZH} 2$ is the enzymatic member of the polycomb repressor complex PRC2, which catalyzes trimethylation of the histone $\mathrm{H} 3$ at lysine 27. In cooperation with PRC1, HDAC, and DNMT and their respective roles in histone ubiquitination, histone deacetylation and DNA methylation, EZH2 induces chromatin compaction and epigenetic silencing of key tumor suppressor genes, which subsequently result in tumorigenesis and metastasis. EZH2 itself can be regulated through multiple pathways transcriptionally (by E2F, p53 and Myc), post-transcriptionally (by microRNAs), and post-translationally (by Akt-mediated phosphorylation). Molecular targeting of EZH2 as well as its collaborative partners, such as HDAC and DNMT, provides important lines for the development of therapeutic strategies to target $\mathrm{EZH} 2$-high tumors such as the currently lethal, late-stage metastatic prostate cancer.

miR-200b, miR-200c, miR-203, are transcriptionally repressed by $\mathrm{EZH} 2$. Since these miRNAs are normally involved in the regulation of $\mathrm{PRC} 1$ proteins, their repression by $\mathrm{EZH} 2$ in turn leads to de-repression, or essentially upregulation, of components of PRC1. Therefore, this mechanism demonstrates a positive feedback loop between PRC2 and PRC1 and establishes a molecular link between the two epigenetic repressor complexes.

In Drosophila, upon recognition of PcG response elements (PREs), specific DNA sequences located upstream of target genes to allow recruitment of corresponding histone-modifying enzymes, EZH2 contained in the PRC2 complex will bind to the PRE and catalyze the methylation of H3K27. However, similar motifs have not been identified in vertebrates (Chase and Cross, 2011). Alternatively, mechanisms for recruitment via intermediary molecules such as the transcription factor YinYang1 (YY1) (Caretti et al., 2004; Wilkinson et al., 2006; Morey and Helin, 2010), the long noncoding RNA HOX transcript antisense RNA (HOTAIR) (Rinn et al., 2007; Gupta et al., 2010; Tsai et al., 2010), nuclear inhibitor of protein Ser/Thr phosphase-1 (NPP1) (Van Dessel et al., 2010), and Jarid2 (Landeira and Fisher, 2011), have been suggested with supporting evidence to anchor PRC2 to DNA.

Aside from the PRC components, EZH2 is also known to interact with other epigenetic machineries including histone deacetylases (HDACs) (van der Vlag and Otte, 1999) as well as the aformentioned DNA methyltransferases (DNMTs) (Vire et al., 2006). While HDAC activity and histone deacetylation 
are required for EZH2-mediated H3K27 methylation, this methylation in turn is thought to predispose DNA to methylation by DNMTs, which eventually lead to irreversible epigenetic silencing of the target genes.

\section{EZH2 IS A PROGNOSTIC BIOMARKER OF SOLID TUMORS SUCH AS PROSTATE CANCER}

EZH2 was first found to associate with prostate cancer in 2002 by a cDNA microarray study which demonstrated its upregulation in metastatic prostate cancer (Varambally et al., 2002). In this profiling report, EZH2 was highlighted as the most significantly upregulated gene when comparing metastatic cancer to localized. In addition, tissue microarray analysis was done to validate the results and evaluate EZH2 protein expression in situ in a collection of prostate tissues. The outcome indicated a positive relationship between EZH2 protein level and disease aggressiveness (Varambally et al., 2002). Several follow-up studies later also confirmed that expression of EZH2 shows a correlated pattern with the stage of prostate cancer development (Berezovska et al., 2006; Saramaki et al., 2006; Hoffmann et al., 2007). Moreover, not only is EZH2 overexpressed in metastatic prostate cancer, its overabundance is observed in localized cancers with a higher risk of recurrence after radical prostatectomy (Varambally et al., 2002). Therefore, concordantly these findings corroborate the idea that $\mathrm{EZH} 2$ can serve as a useful biomarker for diagnostic and prognostic purposes in prostate cancer, with respect to risk assessment and outcome prediction.

Similarly, elevated EZH2 was also found in invasive and metastatic breast cancer, where increased level of the protein is a strong indicator of poor clinical outcome (Kleer et al., 2003). Moreover, individual groups have consistently reported that, $\mathrm{EZH} 2$ also exhibits overexpression in other types of solid tumors found in bladder cancer (Arisan et al., 2005; Raman et al., 2005; Weikert et al., 2005), gastric cancer (Matsukawa et al., 2006), lung cancer (Watanabe et al., 2008), and hepatocellular carcinoma (Sudo et al., 2005). It is interesting to note that, in contrast to the overexpression pattern of EZH2 in solid tumor cancers, EZH2 aberrations are manifested in the form of point mutations in lymphoma and myeloid neoplasms, suggesting that EZH2 mutations exist in a cancer type-specific manner (Morin et al., 2010; Sneeringer et al., 2010).

\section{REGULATION OF EZH2 AND CROSSTALK WITH OTHER SIGNALING PATHWAYS}

As an important epigenetic regulator EZH2 itself is also tightly regulated. Tremendous efforts have been made throughout the years towards understanding EZH2's regulation in normal and cancerous cells. Studies provide compelling evidence that EZH2 expression can be controlled at the transcriptional, posttranscriptional, as well as post-translational levels (Fig. 1). The transcription factors E2Fs have been indicated to bind to the promoters of both EZH2 and EED to transactivate their expression, which provide one mechanistic basis for E2F-mediated cell proliferation (Bracken et al., 2003). On the other hand, the well-established tumor suppressor p53 is found to be involved in EZH2's transcriptional regulation, as it can act to repress the promoter of EZH2 to maintain genetic stability (Tang et al., 2004). Therefore cancer progression associated with loss of p53 is partially attributable to the increased activity of histone methylation as a consequence of EZH2 de-repression.

More specifically for prostate cancer, in addition to transcriptional regulation, EZH2 expression has been shown to be also modulated at the post-transcriptional level by miRNAs. Over the years miR-101, miR-26a, and miR-26b have been recognized to be significantly decreased in prostate cancer through miRNA profiling studies (Lu et al., 2005; Volinia et al., 2006; Porkka et al., 2007; Ozen et al., 2008). By targeting the 3' untranslated region (UTR) of EZH2 mRNA, ectopically expressed miR-101 was able to repress endogenous EZH2 expression in multiple prostate cancer cell lines and consequently leading to increased tumorigenic potential and cell migration (Varambally et al., 2008; Cao et al., 2010). Meanwhile, miR-26a was shown to inhibit EZH2 expression in the androgen-independent prostate cancer cell line DU145 that models the metastatic stage of prostate carcinoma (Varambally et al., 2008). Similarly, another group of miRNAs belonging to the let-7 family have also been identified as regulators of EZH2 (Kong et al., 2012). Having been characterized to have tumor suppressor activities, the let-7 miRNAs target EZH2 transcript to degradation and result in reduced clonogenic ability of prostate cancer cells when overexpressed. These negative regulatory roles of miR-101, miR-26a and let-7 for $\mathrm{EZH} 2$ are consistent with their genomic loss that have been reported in localized as well as metastatic prostate cancer cells, which have concordantly increased EZH2 levels (Varambally et al., 2008; Kong et al., 2012).

More recently, Myc, a prominent oncogenic transcription factor involved in multiple cellular processes including DNA replication, protein synthesis, cell cycle progression, cellular metabolism, chromatin structure, stem cell fate and differentiation (Dang et al., 2006; Meyer and Penn, 2008), has been demonstrated to regulate the methyltransferase $\mathrm{EZH} 2$, both at the transcriptional and post-transcriptional level (Koh et al., 2011). Evidence has been provided that Myc is able to stimulate $\mathrm{EZH} 2$ 's transcription by directly binding to its promoter, thus increasing the mRNA amount of EZH2. Simultaneously, Myc is also reportedly a capable repressor of transcription of the host gene encoding miR-26a and miR-26b (Chang et al., 2008), which consequently can lead to the de-repression of $E Z H 2$, resulting in an increase in its protein level (Koh et al., 2011). These two distinct mechanisms enforced by Myc synergistically induce $\mathrm{EZH} 2$ expression, contributing considerably to prostate cell transformation and carcinogenesis.

Furthermore, post-translationally EZH2 is a downstream target of the phosphoinositide 3-kinase (PI3K)-Akt signaling pathway which is involved in cell survival, proliferation, growth and motility. It has been shown that activated Akt phosphorylates $E Z H 2$ at serine 21, resulting in diminished affinity of EZH2 to $\mathrm{H} 3$ thus compromising its catalytic activity (Cha et al., 2005). 
As observed in many cellular processes, EZH2 function can also be affected by collaborating transcription factors. This can be exemplified by the crosstalk between AR signaling and $\mathrm{EZH} 2$ in prostate cancer, as evidenced by a recent genomewide study (Zhao et al., 2012). It is now understood that AR, which has always been thought as a transcriptional activator involved in prostate development, in fact can also act globally as a gene suppressor via its interaction with $\mathrm{EZH} 2$ and the downstream $\mathrm{H} 3 \mathrm{~K} 27$ trimethylation. As a result, through the coordination of both molecules, genes associated with nonprostatic differentiation are intensely repressed, which in turn gives rise to cancerous de-differentiation in the prostate (Zhao et al., 2012). This intriguing finding not only uncovers a novel role of AR but also delineates the multifaceted characteristics of $\mathrm{EZH} 2$ and its substantial relevance in prostate cancer development.

\section{DOWNSTREAM TARGETS OF EZH2 AND ETIOLOGICAL IMPLICATIONS}

As a histone methyltransferase, EZH2 regulates a myriad of target genes and contributes to various aspects of the development of prostate cancer through the transcriptional repression of these tumor/metastasis suppressor genes. In prostate cancer it has been found that a wide array of genes, all of which are associated with cancer progression and metastasis when silenced, are identified as direct targets of EZH2 (Table 1), corroborating the belief of $\mathrm{EZH} 2$ being a bona fide oncogene.

It was first demonstrated that $\mathrm{EZH} 2$ can activate Ras and NF-KB pathway by epigenetically silencing disabled homolog2interacting protein (DAB2IP), a RasGAP gene which serves as a scaffold in the signaling transduction of Ras and NF-KB (Chen et al., 2005; Min et al., 2010). The ultimate end result is promotion of initiation and metastasis of prostatic tumors. Moreover, an integrative genomics analysis has discovered that EZH2 can repress the expression of adrenergic receptor beta-2 (ADRB2), a critical mediator of the beta-adrenergic signaling pathway, ultimately resulting in cellular transformation and cell invasion (Yu et al., 2007a). Another reported targeted gene of $\mathrm{EZH} 2$ is $\mathrm{CDH} 1$, which encodes for the epithelial marker E-cadherin, whose loss often demarcates epithelialto-mesenchymal transition (Cao et al., 2008). Through histone $\mathrm{H} 3 \mathrm{~K} 27$ trimethylation, $\mathrm{EZH} 2$ binds to the promoter of Ecadherin and silences its expression, leading to acquisition of cancer cell invasiveness and progression to advanced tumor stage. In a similar manner, tumor suppressors prostatic inhibin (PSP94) and human homolog of Drosophila slit2 (SLIT2) are also discovered to be downstream targets of $\mathrm{EZH} 2$ in prostate cancer and involved in tumorigenesis (Beke et al., 2007; Yu et al., 2010a). PSP94, as encoded by the gene MSMB, is known to promote prostatic tumor cell apoptosis, inhibit secretion of a matrix metalloproteinase (MMP) and decrease VEGF-mediated angiogenesis, and therefore its suppression by $\mathrm{EZH} 2$ via $\mathrm{H} 3 \mathrm{~K} 27$ trimethylation is causally related to the progression of prostate cancer to advanced stages (Beke et al., 2007). Mean- while, SLIT2 the chemorepellent protein functions as a tumor suppressor by inhibiting cell migration towards specific chemotactic factors. Therefore, overexpressed EZH2 in prostate cells induces epigenetic silencing of the gene and consequently exacerbates prostate cell proliferation and invasion (Yu et al., 2010a). More recently, a direct link between EZH2 and MMPs TIMP2 and TIMP3 (tissue inhibitors of metalloproteinases) has also been established, which illustrates another mechanism by which EZH2 can lead to degradation of extracellular matrix (ECM) and subsequently cell invasion through its suppressive activity of target genes (Shin and Kim, 2012). In addition, a novel tumor and metastasis suppressor Raf-1 kinase inhibitor protein (RKIP) has been lately confirmed to be negatively regulated by $\mathrm{EZH} 2$, and loss of RKIP results in prostate cancer advancement and metastasis due to disruption of a number of major cellular signaling pathways including Raf-1/MEK/ERK, NF-kB, and GPCR (Ren et al., 2012).

Intriguingly, fueled by the high-throughput RNA-sequencing technology a group of researchers recently characterized a type of RNA, long intergenic noncoding RNA (lincRNA), that becomes deregulated in prostate cancer by EZH2-mediated H3K27 trimethylation (Prensner et al., 2011). Over a hundred prostate tissues and cell lines were examined in the study, and through comprehensive bioinformatic analyses 121 prostate cancer-associated noncoding RNA transcripts (PCATs) were brought to light. The PCATs exhibited differential expression patterns according to disease severity, clearly distinguishing benign, localized or metastatic prostate cancer samples. Among them PCAT-1 was of particular interest, since it was found to be repressed by the PRC2 complex, as confirmed by an increase in its expression upon knockdown or inhibition of $\mathrm{EZH} 2$.

The above studies of individual genes and lincRNA manifest how EZH2-mediated epigenetic silencing contributes to prostate cancer. As a matter of fact, EZH2 is known to suppress hundreds of target genes that are developmentally important, whose repression contributes to the maintenance of the undifferentiated state of embryonic stem cells (ESCs) (Lee et al., 2006; Pietersen and van Lohuizen, 2008; Kerppola, 2009; Leeb et al., 2010). Similarly, EZH2 upregulation in prostate cancer cells controls a group of tumor suppressor genes reminiscent to those in stem cells, some of which have been exemplified in the aforementioned studies (Lee et al., 2006; Squazzo et al., 2006; Yu et al., 2007b). These pieces of experimental evidence elucidate a fascinating route by which $\mathrm{EZH} 2$ can confer stem cell-like properties in EZH2-overexpressed cells to establish a stem cell-like polycomb repression signature, thus leading to cancer progression. Upon acquisition of elevated EZH2 expression, tumor cells undergo unchecked epigenetic silencing of developmental regulators, which are found to be co-occupied and silenced by transcription factors Oct-4, Sox-2 and Nanog that are known to be critical in establishing ESC identity (Boyer et al., 2006; Lee et al., 2006). Ultimately, the process of de-differentiation, which is an established cancerous phenotype, is observed. 
Table 1. List of repressed targets downstream of EZH2 in cancer

\begin{tabular}{llll}
\hline \multicolumn{2}{l}{ EZH2 targets in prostate cancer } & & \\
Target & Function & Contribution to carcinogenesis & Reference \\
\hline DAB2IP & Inhibition of NF-KB/Ras pathway & Transformation, proliferation and invasion & Chen et al., 2005; Min et al., 2010 \\
ADRB2 & B-adrenergic signaling & Transformation and invasion & Yu et al., 2007 \\
CDH1 & Cell-cell adhesion & Invasion & Cao et al., 2008 \\
PSP94 & Inhibits MMP secretion & Invasion & Beke et al., 2007 \\
SLIT2 & Chemorepellent protein & Proliferation and invasion & Yu et al., 2010 \\
TIMP2/3 & ECM degradation & Invasion & Shin and Kim, 2012 \\
RKIP & Inhibition of Raf and NF-KB pathways & Invasion & Ren et al., 2012 \\
PCAT-1 & Transcriptional repressor lincRNA & Proliferation & Prensner et al., 2011 \\
\hline EZH2 targets in other cancer types & & Reference \\
Target & Function & Cancer type & Du et al., 2012 \\
\hline FOXC1 & Transcription factor for differentiation & Breast cancer & Chang et al., 2011 \\
RAD51 & DNA damage repair protein & Breast cancer & Lee et al., 2008 \\
BMPR1B & Astroglial differentiation & Glioblastoma & Lu et al., 2010 \\
VASH1 & Inhibition of angiogenesis & Ovarian cancer & Hussain et al., 2009 \\
DKK1 & Wnt signaling antagonist & Lung cancer &
\end{tabular}

In addition to the studies of EZH2 target genes in prostate cancer, accumulating evidence confirmed that $\mathrm{EZH} 2$ can also transcriptionally repress a number of target genes in various other cancer types (Table 1). For example, in breast cancer, $\mathrm{EZH} 2$ epigenetically silences the transcription factor FOXC1 as well as a DNA damage repair protein RAD51, both leading to tumor progression in breast tissues (Chang et al., 2011; Du et al., 2012). Other targets of EZH2 include BMPR1B (Lee et al., 2008), VASH1 (Lu et al., 2010), and DKK1 (Hussain et al., 2009), which are manifested in glioma, ovarian and lung cancer, respectively.

\section{PHARMACOLOGICAL TARGETING OF EZH2}

A fundamental difference between genetic and epigenetic phenomena lies within the potential reversibility of each respective process. By definition, genetic alterations are ones occurring in the nucleotide sequence, and therefore once a mutation is acquired it is often difficult to restore the correct sequence or to cope with the affected gene product. On the other hand, epigenetic changes have great potential to be reversed due to their unique way of exerting transcriptional control without disrupting the DNA sequence. Therefore, it is biochemically and molecularly more feasible to develop inhibitors which can modulate the activities of enzymes involved in epigenetic modifications. To date, a number of small molecules have been discovered as inhibitors of key enzymes in cancer epigenomics, and they provide a promising avenue for developing effective pharmacological agents to combat certain diseases which are incurable or resistant to current therapies, including advanced prostate cancer.

It has been accepted knowledge for over two decades that the molecule 3-deazaneplanocin-A (DZNep) can act as a potent inhibitor of the S-adenosyl-L-homocysteine (SAH)—hydrolase, a cofactor known to be required by $\mathrm{EZH} 2$-dependent methylation (Glazer et al., 1986). DZNep was later shown to deplete cellular levels of PRC2 complex proteins including EZH2 and inhibit H3K27me3 (Tan et al., 2007). Thus, DZNep became the first EZH2-targeting compound, and in vivo studies have shown that DZNep can specifically induce apoptosis in cancerous cells without imposing cytotoxicity on normal cells (Tan et al., 2007; Crea et al., 2011). Not only does EZH2 exhibit anti-proliferative properties, it is also demonstrated to deter migration and invasion in prostate cancer cells (Crea et al., 2011). Recognizing the considerable potential displayed by DZNep as an epigenetic therapy for prostate cancer, researchers have committed to developing a formulation of DZNep which can be administered clinically. Due to the short half-life of DZNep in vivo accounted by its hydrophilic nature (Coulombe et al., 1995), very recently a formulation of DZNep encapsulated inside pegylated liposomes was introduced to show improved pharmacokinetic characteristics. This novel approach was able to retard DZNep's turnover rate, prolonging the molecule's retention in the systemic circulation and thus enhancing its pharmacological efficacy (Sun et al., 2012). However, doubts remain about DZNep's therapeutic specificity, since it has been shown to indiscriminately inhibit histone methylation, resulting in a reduction of a combination of histone marks, including not only H3K27me3, but also H3K4me3 which usually mediates active transcription.

Alternative methods for targeting EZH2 activity can be achieved by interruption of enzymes such as HDAC and DNMTs whose activity facilitates EZH2-mediated epigenetic silencing (Fig. 1). Among the recently discovered HDAC inhibitors which have been shown to induce a variety of phenotypic changes including growth arrest, apoptotic cell death and se- 
nescence, suberoylanilide hydroxamic acid (SAHA) and depsipeptide (Romidepsin) are two that have been approved by the FDA, both for the treatment of cutaneous T-cell lymphoma (CTCL) (Xu et al., 2007). SAHA is by far the most advanced HDAC inhibitor in clinical trials, and it inhibits a family of HDAC enzymes by interacting directly with their catalytic sites (Bhalla, 2005). Romidepsin on the other hand is a prodrug which is activated by glutathione-mediated reduction upon its uptake, it then binds to the zinc atom contained in the active site of HDAC enzymes, consequently abolishing their catalytic activities (Furumai et al., 2002). Both SAHA and Romidepsin have been demonstrated to confer growth suppression in prostate cancer cells (Butler et al., 2000; Lai et al., 2008), thus deeming them to be excellent candidate antitumor agents for prostate carcinoma, and may be applied as an adjuvant together with first-line hormone-deprivation therapies. Similarly, DNMT inhibitors, such as 5-aza-2'-deoxycytodine (5-Aza) which is a nucleoside analog, have also been proven effective in promoting apoptosis in prostate cancer cells. The demethylating capability of 5-Aza is manifested by its incorporation into replicating DNA and irreversible binding to DNMTs through covalent interaction to render them inactive. As a result, there is a passive loss of de novo methylation genome-wide (Christman, 2002). However, like DZNep, HDAC and DNMT inhibitors also suffer from major limitations in their epigenetic specificity. There are serious concerns for their application in clinical settings as nontargeted change to one's epigenome may result in unwanted and profound side-effects either in short term or long term.

More recently, a biochemical study performed highthroughput screening assays which processed 2 million compounds in the GlaxoSmithKline (GSK) collection, and was able to identify a molecule GSK-A to exhibit on-target and cellspecific inhibitory activity towards EZH2 (Diaz et al., 2012). It was demonstrated that GSK-A acts as a competitive agonist to the methyltransferase by displacing its endogenous substrate, thus resulting in a marked reduction of H3K27 trimethylation. An in vivo study conducted by a group of researchers using a compound of slightly different chemical structure, GSK126, provided further evidence that pharmacological inhibition of $\mathrm{EZH} 2$ could be achieved in a highly potent and selective manner (McCabe et al., 2012). In lymphoma models where EZH2 mutations lead to hyperactivity, GSK126 can significantly decrease the global level of $\mathrm{H} 3 \mathrm{~K} 27 \mathrm{me} 3$ and de-repress the expression of PRC2 target genes, effectively impeding cell proliferation and tumor growth. With these pieces of compelling empirical evidence it is believed that, due to their high specificity in targeting $\mathrm{EZH} 2$, the GSK compounds hold great promise as a potential therapeutic strategy for prostate cancer.

In addition to the discovery of small molecules which pharmacologically disrupt EZH2's enzymatic functions, recent research progress has also explored the use of chemical compounds to alter EZH's expression level. One group demonstrated that a formulated drug 3,3'-diindolylmethane (abbreviated as BR-DIM, Bio Response, Boulder, $\mathrm{CO}$ ) is able to effectively reduce $\mathrm{EZH} 2$ expression by upregulating let-7 thus enhancing the miRNA-mediated downregulation of EZH2 at the protein level (Kong et al., 2012). In a phase II clinical trial where BR-DIM was administered to prostate cancer patients prior to radical prostatectomy, let-7 was elevated while EZH2 was diminished. This observation was consistent with functional assays that demonstrated decreased self-renewal ability and clonogenic growth of prostate cancer cells upon BR-DIM treatment (Kong et al., 2012). Another compound bearing therapeutic potential towards prostate cancer treatment is 16-hydroxycleroda-3,13-dien-15,16-olide (PL3), which is a natural product isolated from the bark of Polyalthia longifolia. In human leukemia cells, PL3 was found to induce apoptosis through reduction of EZH2 as well as SUZ12, leading to downstream reactivation of PRC2-repressed tumor suppressor genes (Lin et al., 2011). This finding provided a mechanistic link to PL3's previously known anti-inflammatory and cytotoxic activities in other cancer types including breast cancer and hepatocellular carcinoma (Chang et al., 2006), and offers an insightful approach to molecularly target EZH2. Additionally, a well-known anticancer agent, all-trans retinoic acid (ATRA), whose apoptosis-inducing activity has been investigated in leukemia (Drach et al., 1993; Hagiwara et al., 2010), gastric cancer (Hoang et al., 2010) and prostate cancer (Zhang, 2002), is recently evidenced to function through repression of EZH2- and DNMT3Bmediated hypermethylation of HOXB13, a member of the homeobox superfamily and an anti-proliferative transcription factor (Liu et al., 2012). EZH2 is known to recruit DNMT3B to promoter regions of specific gene loci since the latter does not inherently have DNA-binding domains and depends on EZH2's presence in order to carry out DNA methylation (Vire et al., 2006). Upon ATRA treatment, cell growth arrest was observed in androgen-independent prostate cancer DU145 cells, following the marked downregulation of both EZH2 and DNMT3B, as well as reduced methylation and restored expression level of HOXB13 (Liu et al., 2012).

Taken together, EZH2 inhibitors, as well as agents that block HDAC and DNMT functions could possibly be administered in combination with hormone deprivation therapy to prostate cancer patients. These combinatorial approaches may take advantage of both the anti-proliferative effects of chemical/surgical castration therapy and the pro-differentiation effects of epigenetic drugs. In concert they may effectively shrink the tumors without driving the residual cells toward acquisition of stem cell-like properties, thus reducing disease recurrence.

\section{CONCLUSION}

Based on a plethora of evidence emerged in the past decade, it is now indisputable that the histone methylatransferase EZH2 plays a pivotal role in maintaining a cell's epigenomic integrity. Through histone modifications $\mathrm{EZH} 2$ is capable of preserving proper chromatin structures and ensuring appropriate gene expressions, thus exerting controlled regulation on a cohort of tumor and metastasis suppressor genes. Therefore when overexpressed in adult tissues, EZH2 behaves as an oncogene 
and malignant cellular transformation could occur, giving rise to cell de-differentiation, tumorigenesis and ultimately metastasis. Moreover, due to its extensive upregulation in aggressive prostate cancer and its interaction with the AR-signaling pathway, $\mathrm{EZH} 2$ is particularly culpable in prostate cancer's development and progression to advanced disease stages. Since prostate cancer has been regarded as a model of "epigenetic catastrophe" (Yegnasubramanian et al., 2004), it is an ideal system in which epigenetic drugs could be studied. Among those enzymes that can serve as molecular targets for anticancer therapy, EZH2 holds great promise for effectively inducing apoptotic cell death when its activity is abolished in prostate cancer cells. Although there has been progress in generating EZH2 inhibitors for the use of cancer treatment, a more thorough understanding of the multifaceted biological roles of EZH2 is yet to be attained, in order to facilitate the development of pharmacological agents which will demonstrate maximal efficacy and minimal toxicity. Thus, it is believed that EZH2 is a highly encouraging candidate for molecular targeting in prostate cancer treatment, and it presents an innovative approach to combat a disease through epigenetic mechanisms. While it has been challenging to pharmacologically target a transcription factor, recent development on GSK-A and GSK126 as highly specific $\mathrm{EZH} 2$ inhibitors represents the beginning of an exciting era that on-target epigenetic drugs can be translated into clinics and EZH2-high tumors may be effectively treated.

\section{ABBREVIATIONS}

ADRB2, adrenergic receptor beta-2; ATRA, all-trans retinoic acid; CRPC, castration-resistant prostate cancer; CTCL, cutaneous T-cell lymphoma; DAB2IP, disabled homolog2-interacting protein; DZNep, 3-deazaneplanocin-A; DNMT, DNA methyltransferase; ECM, extracellular matrix; ESC, embryonic stem cell; EZH2, enhancer of zeste homolog 2; HDAC, histone deacetylase; HDT, ormone deprivation therapy; HOTAIR, HOX transcript antisense RNA; lincRNA, long intergenic noncoding RNA; miRNA, microRNA; MMP, matrix metalloproteinase; NPP1, nuclear inhibitor of protein Ser/Thr phosphase-1; PCAT, prostate cancer-associated noncoding RNA transcript; PcG, polycomb group; PI3K, phosphoinositide 3-kinase; PRC, polycomb repressive complex; PRE, PcG response element; RBBP4, retinoblastoma binding protein 4; RKIP, Raf-1 kinase inhibitor protein; SAH, S-adenosyl-Lhomocysteine; SAHA, suberoylanilide hydroxamic acid; SUZ12, suppressor of zeste 12; TrxG, trithorax group; UTR, untranslated region; YY1, YinYang1

\section{REFERENCES}

Arisan, S., Buyuktuncer, E.D., Palavan-Unsal, N., Caskurlu, T., Cakir, O.O., and Ergenekon, E. (2005). Increased expression of EZH2, a polycomb group protein, in bladder carcinoma. Urol Int 75, 252-257.

Beke, L., Nuytten, M., Van Eynde, A., Beullens, M., and Bollen, M. (2007). The gene encoding the prostatic tumor suppressor PSP94 is a target for repression by the Polycomb group protein EZH2. Oncogene 26, 4590-4595.

Berezovska, O.P., Glinskii, A.B., Yang, Z., Li, X.M., Hoffman, R.M., and Glinsky, G.V. (2006). Essential role for activation of the Polycomb group $(\mathrm{PcG}$ ) protein chromatin silencing pathway in metastatic prostate cancer. Cell Cycle 5, 1886-1901.

Berry, W., Dakhil, S., Modiano, M., Gregurich, M., and Asmar, L. (2002). Phase III study of mitoxantrone plus low dose prednisone versus low dose prednisone alone in patients with asymptomatic hormone refractory prostate cancer. J Urol 168, 2439-2443.

Bhalla, K.N. (2005). Epigenetic and chromatin modifiers as targeted therapy of hematologic malignancies. J Clin Oncol 23, 3971-3993.

Boyer, L.A., Plath, K., Zeitlinger, J., Brambrink, T., Medeiros, L.A., Lee, T.I., Levine, S.S., Wernig, M., Tajonar, A., Ray, M.K., et al. (2006). Polycomb complexes repress developmental regulators in murine embryonic stem cells. Nature 441, 349-353.

Bracken, A.P., Pasini, D., Capra, M., Prosperini, E., Colli, E., and Helin, K. (2003). EZH2 is downstream of the pRB-E2F pathway, essential for proliferation and amplified in cancer. EMBO J 22, 5323-5335.

Butler, L.M., Agus, D.B., Scher, H.I., Higgins, B., Rose, A., CordonCardo, C., Thaler, H.T., Rifkind, R.A., Marks, P.A., and Richon, V.M. (2000). Suberoylanilide hydroxamic acid, an inhibitor of histone deacetylase, suppresses the growth of prostate cancer cells in vitro and in vivo. Cancer Res 60, 5165-5170.

Cao, P., Deng, Z., Wan, M., Huang, W., Cramer, S.D., Xu, J., Lei, M., and Sui, G. (2010). MicroRNA-101 negatively regulates Ezh2 and its expression is modulated by androgen receptor and HIF-1alpha/ HIF-1beta. Mol Cancer 9, 108.

Cao, Q., Mani, R.S., Ateeq, B., Dhanasekaran, S.M., Asangani, I.A., Prensner, J.R., Kim, J.H., Brenner, J.C., Jing, X., Cao, X., et al. (2011). Coordinated regulation of polycomb group complexes through microRNAs in cancer. Cancer Cell 20, 187-199.

Cao, Q., Yu, J., Dhanasekaran, S.M., Kim, J.H., Mani, R.S., Tomlins, S.A., Mehra, R., Laxman, B., Cao, X., Yu, J., et al. (2008). Repression of E-cadherin by the polycomb group protein $\mathrm{EZH} 2$ in cancer. Oncogene 27, 7274-7284.

Cao, R., Wang, L., Wang, H., Xia, L., Erdjument-Bromage, H., Tempst, P., Jones, R.S., and Zhang, Y. (2002). Role of histone H3 lysine 27 methylation in Polycomb-group silencing. Science 298, 1039-1043.

Caretti, G., Di Padova, M., Micales, B., Lyons, G.E., and Sartorelli, V. (2004). The Polycomb Ezh2 methyltransferase regulates muscle gene expression and skeletal muscle differentiation. Genes Dev 18, 2627-2638.

Center, M., Siegel, R., and Ahmedin, J. (2011). Global Cancer Facts \& Figures 2nd Edition, A.C. Society, ed. (Atlanta, American Cancer Society)

Cha, T.L., Zhou, B.P., Xia, W., Wu, Y., Yang, C.C., Chen, C.T., Ping, B., Otte, A.P., and Hung, M.C. (2005). Akt-mediated phosphorylation of EZH2 suppresses methylation of lysine 27 in histone H3. Science 310, 306-310.

Chang, C.J., Yang, J.Y., Xia, W., Chen, C.T., Xie, X., Chao, C.H., Woodward, W.A., Hsu, J.M., Hortobagyi, G.N., and Hung, M.C. (2011). EZH2 promotes expansion of breast tumor initiating cells through activation of RAF1-beta-catenin signaling. Cancer Cell 19, 86-100.

Chang, F.R., Hwang, T.L., Yang, Y.L., Li, C.E., Wu, C.C., Issa, H.H., Hsieh, W.B., and Wu, Y.C. (2006). Anti-inflammatory and cytotoxic diterpenes from formosan Polyalthia longifolia var. pendula. Planta Med 72, 1344-1347.

Chang, T.C., Yu, D., Lee, Y.S., Wentzel, E.A., Arking, D.E., West, K.M., Dang, C.V., Thomas-Tikhonenko, A., and Mendell, J.T. (2008). 
Widespread microRNA repression by Myc contributes to tumorigenesis. Nature Genet 40, 43-50.

Chase, A., and Cross, N.C. (2011). Aberrations of EZH2 in cancer. Clin Cancer Research 17, 2613-2618.

Chen, H., Tu, S.W., and Hsieh, J.T. (2005). Down-regulation of human DAB2IP gene expression mediated by polycomb Ezh2 complex and histone deacetylase in prostate cancer. J Biol Chem 280, 22437-22444.

Christman, J.K. (2002). 5-Azacytidine and 5-aza-2'-deoxycytidine as inhibitors of DNA methylation: mechanistic studies and their implications for cancer therapy. Oncogene 21, 5483-5495.

Coulombe, R.A., Jr., Sharma, R.P., and Huggins, J.W. (1995). Pharmacokinetics of the antiviral agent 3-deazaneplanocin A. Eur J Drug Metab Pharmacokinet 20, 197-202.

Crea, F., Hurt, E.M., Mathews, L.A., Cabarcas, S.M., Sun, L., Marquez, V.E., Danesi, R., and Farrar, W.L. (2011). Pharmacologic disruption of Polycomb Repressive Complex 2 inhibits tumorigenicity and tumor progression in prostate cancer. Mol Cancer 10, 40.

Czermin, B., Melfi, R., McCabe, D., Seitz, V., Imhof, A., and Pirrotta, V. (2002). Drosophila enhancer of Zeste/ESC complexes have a histone $\mathrm{H} 3$ methyltransferase activity that marks chromosomal Polycomb sites. Cell 111, 185-196.

Dang, C.V., O'Donnell, K.A., Zeller, K.I., Nguyen, T., Osthus, R.C., and Li, F. (2006). The c-Myc target gene network. Semin Cancer Biol 16, 253-264.

Denmeade, S.R., and Isaacs, J.T. (2002). A history of prostate cancer treatment. Nature reviews. Cancer 2, 389-396.

Diaz, E., Machutta, C.A., Chen, S., Jiang, Y., Nixon, C., Hofmann, G., Key, D., Sweitzer, S., Patel, M., Wu, Z., et al. (2012). Development and validation of reagents and assays for $\mathrm{EZH} 2$ peptide and nucleosome high-throughput screens. J Biomol Screen 17. 1279-1292.

Drach, J., Lopez-Berestein, G., McQueen, T., Andreeff, M., and Mehta, K. (1993). Induction of differentiation in myeloid leukemia cell lines and acute promyelocytic leukemia cells by liposomal all-transretinoic acid. Cancer Res 53, 2100-2104.

Du, J., Li, L., Ou, Z., Kong, C., Zhang, Y., Dong, Z., Zhu, S., Jiang, H., Shao, Z., Huang, B., et al. (2012). FOXC1, a target of polycomb, inhibits metastasis of breast cancer cells. Breast Cancer Res Treat 131, 65-73.

Enokida, H., Shiina, H., Urakami, S., Igawa, M., Ogishima, T., Li, L.C., Kawahara, M., Nakagawa, M., Kane, C.J., Carroll, P.R., et al. (2005). Multigene methylation analysis for detection and staging of prostate cancer. Clinical Cancer Res 11, 6582-6588.

Ferlay, J., Shin, H.R., Bray, F., Forman, D., Mathers, C., and Parkin, D.M. (2010). Estimates of worldwide burden of cancer in 2008: GLOBOCAN 2008. Int J Cancer 127, 2893-2917.

Furumai, R., Matsuyama, A., Kobashi, N., Lee, K.H., Nishiyama, M., Nakajima, H., Tanaka, A., Komatsu, Y., Nishino, N., Yoshida, M., et al. (2002). FK228 (depsipeptide) as a natural prodrug that inhibits class I histone deacetylases. Cancer research 62, 4916-4921.

Gibbons, R.J. (2005). Histone modifying and chromatin remodelling enzymes in cancer and dysplastic syndromes. Human Mol Genet 14 Spec No 1, R85-92.

Glazer, R.I., Hartman, K.D., Knode, M.C., Richard, M.M., Chiang, P.K., Tseng, C.K., and Marquez, V.E. (1986). 3-Deazaneplanocin: a new and potent inhibitor of S-adenosylhomocysteine hydrolase and its effects on human promyelocytic leukemia cell line HL-60. Biochem
Biophys Res Commun 135, 688-694.

Gupta, R.A., Shah, N., Wang, K.C., Kim, J., Horlings, H.M., Wong, D.J., Tsai, M.C., Hung, T., Argani, P., Rinn, J.L., et al. (2010). Long non-coding RNA HOTAIR reprograms chromatin state to promote cancer metastasis. Nature 464, 1071-1076.

Hagiwara, Y., Kasukabe, T., Kaneko, Y., Niitsu, N., and Okabe-Kado, J. (2010). Ellagic acid, a natural polyphenolic compound, induces apoptosis and potentiates retinoic acid-induced differentiation of human leukemia HL-60 cells. Int J Hemat 92, 136-143.

Higano, C.S., Schellhammer, P.F., Small, E.J., Burch, P.A., Nemunaitis, J., Yuh, L., Provost, N., and Frohlich, M.W. (2009). Integrated data from 2 randomized, double-blind, placebo-controlled, phase 3 trials of active cellular immunotherapy with sipuleucel-T in advanced prostate cancer. Cancer 115, 3670-3679.

Hoang, T.C., Bui, T.K., Taguchi, T., Watanabe, T., and Sato, Y. (2010). All-trans retinoic acid inhibits KIT activity and induces apoptosis in gastrointestinal stromal tumor GIST-T1 cell line by affecting on the expression of survivin and Bax protein. J Eep Clin Cancer Res 29, 165.

Hoffmann, M.J., Engers, R., Florl, A.R., Otte, A.P., Muller, M., and Schulz, W.A. (2007). Expression changes in EZH2, but not in BMl1, SIRT1, DNMT1 or DNMT3B are associated with DNA methylation changes in prostate cancer. Cancer Biolo Ther 6, 1403-1412.

Howlader, N., Noone, A.M., Krapcho, M., Neyman, N., Aminou, R., Altekruse, S.F., Kosary, C.L., Ruhl, L., Tatalovich, Z., Cho, H., et al. (2011). SEER Cancer Statistics Review, 1975-2009 (National Cancer Institute).

Hussain, M., Rao, M., Humphries, A.E., Hong, J.A., Liu, F., Yang, M., Caragacianu, D., and Schrump, D.S. (2009). Tobacco smoke induces polycomb-mediated repression of Dickkopf-1 in lung cancer cells. Cancer Res 69, 3570-3578.

Kantoff, P.W., Higano, C.S., Shore, N.D., Berger, E.R., Small, E.J., Penson, D.F., Redfern, C.H., Ferrari, A.C., Dreicer, R., Sims, R.B., et al. (2010a). Sipuleucel-T immunotherapy for castration-resistant prostate cancer. New Eng J Med 363, 411-422.

Kantoff, P.W., Schuetz, T.J., Blumenstein, B.A., Glode, L.M., Bilhartz, D.L., Wyand, M., Manson, K., Panicali, D.L., Laus, R., Schlom, J., et al. (2010b). Overall survival analysis of a phase II randomized controlled trial of a Poxviral-based PSA-targeted immunotherapy in metastatic castration-resistant prostate cancer. J Clin Oncol 28, 1099-1105.

Kerppola, T.K. (2009). Polycomb group complexes--many combinations, many functions. Trends Cell Biol 19, 692-704.

Kleer, C.G., Cao, Q., Varambally, S., Shen, R., Ota, I., Tomlins, S.A., Ghosh, D., Sewalt, R.G., Otte, A.P., Hayes, D.F., et al. (2003). $\mathrm{EZH} 2$ is a marker of aggressive breast cancer and promotes neoplastic transformation of breast epithelial cells. Proc Natl Acad Sci U S A 100, 11606-11611.

Knudsen, B.S., and Vasioukhin, V. (2010). Mechanisms of prostate cancer initiation and progression. Adv Cancer Res 109, 1-50.

Koh, C.M., Iwata, T., Zheng, Q., Bethel, C., Yegnasubramanian, S., and De Marzo, A.M. (2011). Myc enforces overexpression of EZH2 in early prostatic neoplasia via transcriptional and post-transcriptional mechanisms. Oncotarget 2, 669-683.

Kong, D., Heath, E., Chen, W., Cher, M.L., Powell, I., Heilbrun, L., Li, Y., Ali, S., Sethi, S., Hassan, O., et al. (2012). Loss of let-7 upregulates $\mathrm{EZH} 2$ in prostate cancer consistent with the acquisition of cancer stem cell signatures that are attenuated by BR-DIM. PloS 
One 7, e33729.

Kumar-Sinha, C., Tomlins, S.A., and Chinnaiyan, A.M. (2008). Recurrent gene fusions in prostate cancer. Nature reviews. Cancer 8 , 497-511.

Lai, M.T., Yang, C.C., Lin, T.Y., Tsai, F.J., and Chen, W.C. (2008). Depsipeptide (FK228) inhibits growth of human prostate cancer cells. Urol Oncol 26, 182-189.

Landeira, D., and Fisher, A.G. (2011). Inactive yet indispensable: the tale of Jarid2. Trends Cell Biol 21, 74-80.

Lassi, K., and Dawson, N.A. (2009). Emerging therapies in castrateresistant prostate cancer. Curr Opinion Oncol 21, 260-265.

Lee, J., Son, M.J., Woolard, K., Donin, N.M., Li, A., Cheng, C.H., Kotliarova, S., Kotliarov, Y., Walling, J., Ahn, S., et al. (2008). Epigenetic-mediated dysfunction of the bone morphogenetic protein pathway inhibits differentiation of glioblastoma-initiating cells. Cancer Cell 13, 69-80.

Lee, T.I., Jenner, R.G., Boyer, L.A., Guenther, M.G., Levine, S.S., Kumar, R.M., Chevalier, B., Johnstone, S.E., Cole, M.F., Isono, K., et al. (2006). Control of developmental regulators by Polycomb in human embryonic stem cells. Cell 125, 301-313.

Leeb, M., Pasini, D., Novatchkova, M., Jaritz, M., Helin, K., and Wutz, A. (2010). Polycomb complexes act redundantly to repress genomic repeats and genes. Genes Dev 24, 265-276.

Li, L.C., Okino, S.T., and Dahiya, R. (2004). DNA methylation in prostate cancer. Biochim Biophys Acta 1704, 87-102.

Lin, Y.H., Lee, C.C., Chang, F.R., Chang, W.H., Wu, Y.C., and Chang, J.G. (2011). 16-hydroxycleroda-3,13-dien-15,16-olide regulates the expression of histone-modifying enzymes PRC2 complex and induces apoptosis in CML K562 cells. Life Sci 89, 886-895.

Liu, Z., Ren, G., Shangguan, C., Guo, L., Dong, Z., Li, Y., Zhang, W., Zhao, L., Hou, P., Zhang, Y., et al. (2012). ATRA inhibits the proliferation of DU145 prostate cancer cells through reducing the methylation level of HOXB13 gene. PloS One 7, e40943.

Lu, C., Han, H.D., Mangala, L.S., Ali-Fehmi, R., Newton, C.S., Ozbun, L., Armaiz-Pena, G.N., Hu, W., Stone, R.L., Munkarah, A., et al. (2010). Regulation of tumor angiogenesis by EZH2. Cancer Cell 18, 185-197.

Lu, J., Getz, G., Miska, E.A., Alvarez-Saavedra, E., Lamb, J., Peck, D., Sweet-Cordero, A., Ebert, B.L., Mak, R.H., Ferrando, A.A., et al. (2005). MicroRNA expression profiles classify human cancers. Nature 435, 834-838.

Matsukawa, Y., Semba, S., Kato, H., Ito, A., Yanagihara, K., and Yokozaki, H. (2006). Expression of the enhancer of zeste homolog 2 is correlated with poor prognosis in human gastric cancer. Cancer Sci 97, 484-491.

McCabe, M.T., Ott, H.M., Ganji, G., Korenchuk, S., Thompson, C., Van Aller, G.S., Liu, Y., Graves, A.P., lii, A.D., Diaz, E., et al. (2012). $\mathrm{EZH} 2$ inhibition as a therapeutic strategy for lymphoma with EZH2activating mutations. Nature.

Meyer, N., and Penn, L.Z. (2008). Reflecting on 25 years with MYC. Nature Rev Cancer 8, 976-990.

Min, J., Zaslavsky, A., Fedele, G., McLaughlin, S.K., Reczek, E.E., De Raedt, T., Guney, I., Strochlic, D.E., Macconaill, L.E., Beroukhim, R., et al. (2010). An oncogene-tumor suppressor cascade drives metastatic prostate cancer by coordinately activating Ras and nuclear factor-kappaB. Nature Med 16, 286-294.

Morey, L., and Helin, K. (2010). Polycomb group protein-mediated re- pression of transcription. Trends Bio Sci 35, 323-332.

Morin, R.D., Johnson, N.A., Severson, T.M., Mungall, A.J., An, J., Goya, R., Paul, J.E., Boyle, M., Woolcock, B.W., Kuchenbauer, F., et al. (2010). Somatic mutations altering EZH2 (Tyr641) in follicular and diffuse large B-cell lymphomas of germinal-center origin. Nature genetics $42,181-185$.

Muller, J., Hart, C.M., Francis, N.J., Vargas, M.L., Sengupta, A., Wild, B., Miller, E.L., O'Connor, M.B., Kingston, R.E., and Simon, J.A. (2002). Histone methyltransferase activity of a Drosophila Polycomb group repressor complex. Cell 111, 197-208.

Nelson, W.G., De Marzo, A.M., and Yegnasubramanian, S. (2009). Epigenetic alterations in human prostate cancers. Endocrinology 150, 3991-4002.

Ozen, M., Creighton, C.J., Ozdemir, M., and Ittmann, M. (2008). Widespread deregulation of microRNA expression in human prostate cancer. Oncogene 27, 1788-1793.

Pienta, K.J., and Bradley, D. (2006). Mechanisms underlying the development of androgen-independent prostate cancer. Clin Cancer Res 12, 1665-1671.

Pietersen, A.M., and van Lohuizen, M. (2008). Stem cell regulation by polycomb repressors: postponing commitment. Current opinion in cell biology 20, 201-207.

Porkka, K.P., Pfeiffer, M.J., Waltering, K.K., Vessella, R.L., Tammela, T.L., and Visakorpi, T. (2007). MicroRNA expression profiling in prostate cancer. Cancer Res 67, 6130-6135.

Prensner, J.R., Iyer, M.K., Balbin, O.A., Dhanasekaran, S.M., Cao, Q., Brenner, J.C., Laxman, B., Asangani, I.A., Grasso, C.S., Kominsky, H.D., et al. (2011). Transcriptome sequencing across a prostate cancer cohort identifies PCAT-1, an unannotated lincRNA implicated in disease progression. Nature Biotech 29, 742-749.

Raman, J.D., Mongan, N.P., Tickoo, S.K., Boorjian, S.A., Scherr, D.S., and Gudas, L.J. (2005). Increased expression of the polycomb group gene, EZH2, in transitional cell carcinoma of the bladder. Clin Cancer Res 11, 8570-8576.

Rea, S., Eisenhaber, F., O'Carroll, D., Strahl, B.D., Sun, Z.W., Schmid, M., Opravil, S., Mechtler, K., Ponting, C.P., Allis, C.D., et al. (2000). Regulation of chromatin structure by site-specific histone $\mathrm{H} 3$ methyltransferases. Nature 406, 593-599.

Ren, G., Baritaki, S., Marathe, H., Feng, J., Park, S., Beach, S., Bazeley, P.S., Beshir, A.B., Fenteany, G., Mehra, R., et al. (2012). Polycomb protein $\mathrm{EZH} 2$ regulates tumor invasion via the transcriptional repression of the metastasis suppressor RKIP in breast and prostate cancer. Cancer Res 72, 3091-3104.

Rinn, J.L., Kertesz, M., Wang, J.K., Squazzo, S.L., Xu, X., Brugmann, S.A., Goodnough, L.H., Helms, J.A., Farnham, P.J., Segal, E., et al. (2007). Functional demarcation of active and silent chromatin domains in human HOX loci by noncoding RNAs. Cell 129, 13111323.

Saramaki, O.R., Tammela, T.L., Martikainen, P.M., Vessella, R.L., and Visakorpi, T. (2006). The gene for polycomb group protein enhancer of zeste homolog $2(\mathrm{EZH} 2)$ is amplified in late-stage prostate cancer. Genes Chrom Cancer 45, 639-645.

Sauvageau, M., and Sauvageau, G. (2010). Polycomb group proteins: multi-faceted regulators of somatic stem cells and cancer. Cell Stem Cell 7, 299-313.

Schulz, W.A., and Hoffmann, M.J. (2009). Epigenetic mechanisms in the biology of prostate cancer. Semin Cancer Biol 19, 172-180. 
Shapiro, D., and Tareen, B. (2012). Current and emerging treatments in the management of castration-resistant prostate cancer. Exp Rev Anticancer Ther12, 951-964.

Shin, Y.J., and Kim, J.H. (2012). The role of EZH2 in the regulation of the activity of matrix metalloproteinases in prostate cancer cells. Plos One 7, e30393.

Simon, J.A., and Tamkun, J.W. (2002). Programming off and on states in chromatin: mechanisms of Polycomb and trithorax group complexes. Curr Opin Genet Dev 12, 210-218.

Sneeringer, C.J., Scott, M.P., Kuntz, K.W., Knutson, S.K., Pollock, R.M., Richon, V.M., and Copeland, R.A. (2010). Coordinated activities of wild-type plus mutant EZH2 drive tumor-associated hypertrimethylation of lysine 27 on histone H3 (H3K27) in human B-cell lymphomas. Proc Natl Acad Sci U S A 107, 20980-20985.

Sparmann, A., and van Lohuizen, M. (2006). Polycomb silencers control cell fate, development and cancer. Nature Rev Cancer 6, 846-856.

Squazzo, S.L., O'Geen, H., Komashko, V.M., Krig, S.R., Jin, V.X., Jang, S.W., Margueron, R., Reinberg, D., Green, R., and Farnham, P.J. (2006). Suz12 binds to silenced regions of the genome in a cell-type-specific manner. Genome Res 16, 890-900.

Strahl, B.D., and Allis, C.D. (2000). The language of covalent histone modifications. Nature 403, 41-45.

Sudo, T., Utsunomiya, T., Mimori, K., Nagahara, H., Ogawa, K., Inoue, H., Wakiyama, S., Fujita, H., Shirouzu, K., and Mori, M. (2005). Clinicopathological significance of EZH2 mRNA expression in patients with hepatocellular carcinoma. Brit J Cancer 92, 1754-1758.

Sun, F., Li, J., Yu, Q., and Chan, E. (2012). Loading 3-deazaneplanocin A into pegylated unilamellar liposomes by forming transient phenylboronic acid-drug complex and its pharmacokinetic features in Sprague-Dawley rats. Europ J Pharm Biopharm 80, 323-331.

Tan, J., Yang, X., Zhuang, L., Jiang, X., Chen, W., Lee, P.L., Karuturi, R.K., Tan, P.B., Liu, E.T., and Yu, Q. (2007). Pharmacologic disruption of Polycomb-repressive complex 2-mediated gene repression selectively induces apoptosis in cancer cells. Genes Dev 21, 10501063.

Tang, X., Milyavsky, M., Shats, I., Erez, N., Goldfinger, N., and Rotter, V. (2004). Activated p53 suppresses the histone methyltransferase EZH2 gene. Oncogene 23, 5759-5769.

Tsai, M.C., Manor, O., Wan, Y., Mosammaparast, N., Wang, J.K., Lan, F., Shi, Y., Segal, E., and Chang, H.Y. (2010). Long noncoding RNA as modular scaffold of histone modification complexes. Science 329, 689-693.

van der Vlag, J., and Otte, A.P. (1999). Transcriptional repression mediated by the human polycomb-group protein EED involves histone deacetylation. Nature Genet 23, 474-478.

Van Dessel, N., Beke, L., Gornemann, J., Minnebo, N., Beullens, M., Tanuma, N., Shima, H., Van Eynde, A., and Bollen, M. (2010). The phosphatase interactor NIPP1 regulates the occupancy of the histone methyltransferase EZH2 at Polycomb targets. Nucleic Acids Res 38, 7500-7512.

Varambally, S., Cao, Q., Mani, R.S., Shankar, S., Wang, X., Ateeq, B., Laxman, B., Cao, X., Jing, X., Ramnarayanan, K., et al. (2008). Genomic loss of microRNA-101 leads to overexpression of histone methyltransferase EZH2 in cancer. Science 322, 1695-1699.

Varambally, S., Dhanasekaran, S.M., Zhou, M., Barrette, T.R., Kumar-
Sinha, C., Sanda, M.G., Ghosh, D., Pienta, K.J., Sewalt, R.G., Otte, A.P., et al. (2002). The polycomb group protein EZH2 is involved in progression of prostate cancer. Nature 419, 624-629.

Vire, E., Brenner, C., Deplus, R., Blanchon, L., Fraga, M., Didelot, C., Morey, L., Van Eynde, A., Bernard, D., Vanderwinden, J.M., et al. (2006). The Polycomb group protein EZH2 directly controls DNA methylation. Nature 439, 871-874.

Volinia, S., Calin, G.A., Liu, C.G., Ambs, S., Cimmino, A., Petrocca, F., Visone, R., lorio, M., Roldo, C., Ferracin, M., et al. (2006). A microRNA expression signature of human solid tumors defines cancer gene targets. Proc Natl Acad Sci U S A 103, 2257-2261.

Wang, H., Wang, L., Erdjument-Bromage, H., Vidal, M., Tempst, P., Jones, R.S., and Zhang, Y. (2004). Role of histone H2A ubiquitination in Polycomb silencing. Nature 431, 873-878.

Watanabe, H., Soejima, K., Yasuda, H., Kawada, I., Nakachi, I., Yoda, S., Naoki, K., and Ishizaka, A. (2008). Deregulation of histone lysine methyltransferases contributes to oncogenic transformation of human bronchoepithelial cells. Cancer Cell international 8, 15.

Weikert, S., Christoph, F., Kollermann, J., Muller, M., Schrader, M., Miller, K., and Krause, H. (2005). Expression levels of the EZH2 polycomb transcriptional repressor correlate with aggressiveness and invasive potential of bladder carcinomas. Int $\mathrm{J}$ Mol Med 16, 349-353.

Wilkinson, F.H., Park, K., and Atchison, M.L. (2006). Polycomb recruitment to DNA in vivo by the YY1 REPO domain. Proc Natl Acad Sci U S A 103, 19296-19301.

Xu, W.S., Parmigiani, R.B., and Marks, P.A. (2007). Histone deacetylase inhibitors: molecular mechanisms of action. Oncogene 26 , 5541-5552.

Yegnasubramanian, S., Kowalski, J., Gonzalgo, M.L., Zahurak, M., Piantadosi, S., Walsh, P.C., Bova, G.S., De Marzo, A.M., Isaacs, W.B., and Nelson, W.G. (2004). Hypermethylation of CpG islands in primary and metastatic human prostate cancer. Cancer Res 64 , 1975-1986.

Yu, J., Cao, Q., Mehra, R., Laxman, B., Yu, J., Tomlins, S.A., Creighton, C.J., Dhanasekaran, S.M., Shen, R., Chen, G., et al. (2007a). Integrative genomics analysis reveals silencing of beta-adrenergic signaling by polycomb in prostate cancer. Cancer Cell 12, 419-431.

Yu, J., Cao, Q., Yu, J., Wu, L., Dallol, A., Li, J., Chen, G., Grasso, C., Cao, X., Lonigro, R.J., et al. (2010a). The neuronal repellent SLIT2 is a target for repression by EZH2 in prostate cancer. Oncogene 29, 5370-5380.

Yu, J., Yu, J., Mani, R.S., Cao, Q., Brenner, C.J., Cao, X., Wang, X., Wu, L., Li, J., Hu, M., et al. (2010b). An integrated network of androgen receptor, polycomb, and TMPRSS2-ERG gene fusions in prostate cancer progression. Cancer Cell 17, 443-454.

Yu, J., Yu, J., Rhodes, D.R., Tomlins, S.A., Cao, X., Chen, G., Mehra, R., Wang, X., Ghosh, D., Shah, R.B., et al. (2007b). A polycomb repression signature in metastatic prostate cancer predicts cancer outcome. Cancer research 67, 10657-10663.

Zhang, X.K. (2002). Vitamin A and apoptosis in prostate cancer. Endocr Relat Cancer 9, 87-102.

Zhao, J.C., Yu, J., Runkle, C., Wu, L., Hu, M., Wu, D., Liu, J.S., Wang, Q., Qin, Z.S., and Yu, J. (2012). Cooperation between Polycomb and androgen receptor during oncogenic transformation. Genome Res 22, 322-331. 